\title{
Pensamiento asambleario en Argentina (12 herramientas de autoorganización
}

social)

\section{Assembly-oriented thinking in Argentina \\ (12 tools for social self organisation)}

Gradocero

gradocero@riseup.net

\section{Resumen}

Partiendo de la hipótesis de la existencia de un "pensamiento asambleario", entendiendo como tal: a) que hay cosas que se piensan a partir de la existencia de asambleas, no antes; y b) que hay cosas que se piensan en las asambleas y no fuera de ellas; este texto aporta 12 elementos que combinados pretenden componer "máquinas de pensamiento asambleario". El texto se escribe con el propósito de enriquecer la "caja de herramientas" que la autogestión de la comunicación de luchas está construyendo.

Palabras clave: acción política, movimientos sociales, acción colectiva

\section{Abstract}

This text starts on the hypothesis that there is an assembly-oriented thinking. This means that: a) there are things which are though after the existence of assemblies and are not thought before; and $b$ ) that there is though who appears inside the assemblies and not outside them. In this text we contribute with 12 elements which, combined, try to form "assembly-oriented thinking devices". The text has been written to enrich the "tool-box" that the self organization of communication of political action is creating.

Keywords: political action, social movements, collective action

\section{Una introducción}

Argentina. 19 y 20 de diciembre del 2001. Más que una fecha se trata, para nosotros, de un acontecimiento, de un punto de ruptura, de una apertura formidable hacia devenires aún activos.

Incluso para experiencias tan periféricas como gradocero, una publicación esporádica y un difuso colectivo de pensamiento de la ciudad de Rosario. 
A partir del 19 y 20 todos nosotros comenzamos a participar, de manera espontánea, en las asambleas populares de los barrios en que vivíamos. Sin que mediara decisión alguna, el colectivo editorial de nuestra publicación devino un colectivo de asambleístas barriales, un efecto de las asambleas.

Casi inmediatamente comenzamos a proyectar un nuevo número de la revista, concebido como una forma de contagio asambleístico, de "crecimiento por multiplicación" de la lógica asamblearia.

Nuestra hipótesis de trabajo era la siguiente:

Hay pensamiento asambleario.

¿Qué queremos decir con esto?

Al menos dos cuestiones:

01. que hay cosas que pudieron pensarse a partir de la existencia de las asambleas que no se pensaban antes

02. que hay cosas que se piensa en las asambleas que no son pensadas afuera

Desde este punto de partida iniciamos un proceso de búsqueda, de relevamiento de los momentos de emergencia de ese pensamiento múltiple, pero también singular e irreductible.

La investigación devino intervención en julio del 2002, cuando publicamos un nuevo número de la revista, con ocasión de la realización del 1er. Encuentro Regional de Asambleístas de nuestra ciudad. Un intento de transversalización y colectivización de las herramientas militantes producidas por el movimiento asambleario hasta el momento.

Más que intentar representar lo que las asambleas piensan quisimos presentar algunas ideas, retazos, piezas que podían ser combinadas entre sí para componer "máquinas de pensamiento asambleario".

La forma breve y concisa de los escritos, el carácter fragmentario y abierto del conjunto, nos parecieron las maneras más adecuadas de disponer estas ideas para que pudiesen entrar nuevamente en conexión con la praxis cotidiana de las asambleas, en cuyo contexto habían sido producidas. Más que un sistema coherente, un conjunto abierto y heterogéneo: herramientas desordenadas esperando volver a entrar en conexión con las prácticas.

El pensamiento asambleario surge intermitentemente en los textos que presentamos a continuación, en los momentos en que dejan de ser escritos sobre las asambleas y se vuelven parte de la experiencia asamblearia. En el punto en el que son retomados por una asamblea en particular, para intervenir sobre una cuestión específica.

Al poner estos textos en disponibilidad para otros movimientos y experiencias militantes esperamos aportar al enriquecimiento de esa "caja de herramientas global" que la autogestión de la comunicación de las luchas está constituyendo en el mundo entero.

El colectivo editorial de la revista gradocero

Febrero del 2003 


\section{Habitabilidad}

Es posible pensar los sucesos del 19 y 20 como experiencias de deserción masiva del campo de la representación. Como el "punto de catástrofe" a partir del cual una gran cantidad de individuos decidieron declarar inhabitable el espacio organizado por la lógica representativa.

En este sentido, la consigna "que se vayan todos" revela muchas más cosas si nos concentramos no tanto en su significado intrínseco sino en las relaciones entre lo que podríamos llamar "el enunciado" y su "lugar de enunciación”. ¿Desde dónde es posible sostener un enunciado como este?

"Que se vayan todos" es la marca de que muchos de nosotros, a partir del 19 y 20, comenzamos a vivir fuera de la sociedad del espectáculo, que es también el mundo de la representación (la separación público/espectáculo es correlativa a la escisión representantes/representados).

Pero una vez declarado inhabitable el campo de la representación, una vez afuera, nos encontramos con un nuevo problema: Este afuera es un desierto. Es decir, un espacio que, en sus actuales configuraciones, es también inhabitable.

Por lo tanto, dos son las preguntas que pueden organizar la experiencia de las asambleas.

01. ¿cómo volver a hacer habitable la representación?

02. ¿cómo inventar una forma de habitar el afuera de la representación?

La primer pregunta organiza vías de retorno y reforma. La segunda, caminos de invención y fidelidad a la consigna originaria de la experiencia.

Creemos que, si bien no se trata de polarizar innecesariamente entre estas dos preguntas, tendencialmente, la efectivización del retorno al lazo representativo cancela las condiciones que hacen posible la segunda pregunta. $Y$ además, la primer pregunta deja impensado su "lugar de enunciación", no puede dar cuenta del hecho de que estos nuevos modelos de representación sólo pueden ser pensados a partir de ese éxodo violento y masivo de la representación misma que protagonizamos el 19 y el 20.

Por otra parte, asumir una relación de fidelidad con este éxodo implica cierto "desenganche" de los tiempos y los espacios de la representación. La posibilidad de generar ritmos propios y de autonomizar los recorridos subjetivos de los momentos y las instancias organizados por el poder estatal/mercantil.

\section{Crecimiento por expansión y crecimiento por multiplicación}

Una idea surge en una reunión de la asamblea de la Plaza de la Cooperación. Era una reunión para hacer el balance de una actividad realizada por la asamblea: una kermés en la plaza donde ésta se reúne, con puestos de venta de productos artesanales, juegos para chicos y actividades culturales varias (recitales, obras de teatro y espectáculos circenses). En la reflexión sobre la experiencia se va pensando cómo la asamblea va creciendo no tanto por expansión sino por multiplicación: en la kermés comienza a involucrarse gente que no necesariamente venía participando de la asamblea. La 
comisión de la kermés deja de ser "una parte" de la asamblea para convertirse en un espacio autónomo que funciona con la misma lógica asamblearia. Se abren toda una serie de preguntas en relación a cómo la asamblea y la kermés se interrelacionan y se retroalimentan. Va apareciendo esta idea de "crecimiento por multiplicación", donde la asamblea va ayudando a que surjan otros espacios que se organicen de forma horizontal y autónoma, una especie de crecimiento en red, donde cada "nodo" de la red se asocia con otros para crear nuevos nodos. Esta multiplicación tiene como condición que estos nodos sean espacios abiertos a la participación de cualquiera, con lo cual se promueve la circulación de saberes e invenciones entre las distintas experiencias. Espacios localizados donde uno asume una posición ética que luego quiere continuar en los demás lugares que uno habita. De esta manera se va produciendo el contagio: a partir de participar en una asamblea barrial, de hacer esa experiencia, uno luego intenta que sea esa lógica la que funcione en el trabajo, en la facultad, etc. Para continuar este movimiento de reapropiación de espacios de la vida que hace tiempo que no nos pertenecían.

\section{Una vida no-policial}

Decimos que el escenario central de la política representativa (la del Estado y los partidos), con la figura de los políticos hablando aquí y allá, es precisamente eso, un "escenario", un espectáculo que se mira por televisión, se lee en los diarios, se escucha en la radio, se comenta en cada opinión al pasar.

Alejarse de esta relación, la del espectador-espectáculo, significa enfrentarse con la policía. No ya la policía del gatillo fácil que, sabemos, acecha en cada manifestación, en cada esquina del barrio, pues es esta la expresión más brutal de algo que convive mucho más íntimamente en cada uno de nosotros:

El miedo, el escepticismo, las jerarquías, la desconfianza y la sospecha generalizadas, etc.

Los sucesos del 19 y 20 nos pusieron en situación de apagar el televisor y salir a la calle. Una experiencia singular relatada por un asambleísta en una reunión puede servirnos para pensar esto: "La noche del 19, al principio del cacerolazo, yo estaba en mi casa, siguiendo los sucesos por televisión. Tardé en darme cuenta de que en mi barrio también estaban empezando a sonar de a poco las cacerolas, recién cuando el sonido comenzó a ser más fuerte que el del televisor pude convencerme y salí corriendo a la esquina. Esa fue la manera en la que me empecé a involucrar en lo que estaba pasando."

Las asambleas, como continuación del espacio abierto a partir de los cacerolazos, pueden ser pensadas como un paso en la construcción de una vida autónoma, fuera de la "representación", fuera del "escenario" de la política tradicional, una vida no-policial.

\section{Autoorganización abstracta y autoorganización específica}

Las asambleas barriales no son los únicos espacios de autoorganización hoy existentes. Muchas organizaciones piqueteras, sindicales, estudiantiles, sociales, cooperativas, etc. intentan hoy organizarse según esta misma lógica ¿Cuál es la singularidad de las asambleas entonces? Tal vez se trate de que no tengan ninguna. La "singularidad" de la asamblea quizá sea, justamente, que es un 
espacio de "autoorganización abstracta", que no surge a partir de una tarea específica. Nunca se sabe del todo qué rumbo puede ir tomando una asamblea, si su próxima actividad será una compra comunitaria, un escrache, una encuesta o la participación en una marcha. La asamblea puede funcionar como el espacio donde uno va para encontrarse con otros y generar espacios de "autoorganización específica" (p.ej. las comisiones de trabajo) surgidos, estos sí, a partir de una actividad concreta.

\section{La asamblea como red}

Cuando la Asamblea Interbarrial comenzó a experimentarse más como un obstáculo al desarrollo asambleario que como un factor de potenciación de los procesos en curso, las asambleas comenzaron a pensar formas alternativas de coordinación interbarrial, no ya a partir de la construcción de niveles verticales (asamblea barrial-asamblea interbarrial-asamblea nacional) sino intentando complejizar la horizontalidad, generando flujos de comunicación y cooperación transversales entre las asambleas. Empieza a circular la idea de "construir en red". Intentando pensar esto con un grupos compuesto por asambleístas de distintos barrios, durante una reunión zonal de asambleas, surge una idea interesante: además de pensar la construcción interasamblearia en red, se abre la vía de pensar a la asamblea misma como una red: un espacio de articulación y entrecruzamiento de prácticas, saberes, experiencias. Incluso las comisiones de asamblea pueden también pensarse según esta lógica. Se va componiendo entonces un modelo "fractal" donde en cada escala se va multiplicando la misma figura organizativa: la red como el potencial intercambio desjerarquizado entre todos los puntos que la componen.

\section{Las asambleas como espacios de producción de afectos}

En las asambleas se debaten y se construyen proyectos, luchas, espacios pero también, y esto tal vez no sea percibido de manera inmediata, se producen afectos. Hay un tipo específico de afectividad que resulta del encuentro, el diálogo y el trabajo en espacios horizontales, sin jerarquías (ni económicas, ni culturales, ni sexuales, ni generacionales). En las asambleas no se ponen en suspenso las identidades, sino el sistema de jerarquías que las organizaba. De este modo, jóvenes y viejos, hombres y mujeres, trabajadores y desocupados, etc. encuentran un espacio radicalmente distinto en el cual desarrollar relaciones entre sí que van mucho más allá de las tareas puntuales que la asamblea desarrolla en cada momento. Esto es lo que denominamos "un tipo específico de afectividad", una nueva manera de estar juntos, de ser con otros.

\section{¿quiénes somos "nosotros"?}

En las asambleas la gente se va encontrando. Y se va configurando un "nosotros" que no opera por construcción de identidades homogéneas sino por agregación de recursos diferenciados. Hablando de las compras comunitarias Ignacio Lewkowicz, historiador de Bs. As., plantea una definición de ese "nosotros" que nos parece muy cercana:

"La dimensión del nosotros proporciona una potencia de enorme valor. Pero no es que se reconozca lo que cada uno es sino que se valorizan las herramientas que cada uno tiene, y eso subjetivamente 
es muy potente. Aquí se suman operaciones y no personas: la cuestión no es uno o muchos sino que es la composición de las operaciones. No se trata de un nosotros constituido por personas, por yoes.

En nuestro libro, al final, en Sobre las dificultades de un movimiento colectivo tratamos de pensar qué es nosotros. Por un lado, "nosotros" es la persona gramatical más ambigua porque puede ser "yo y tú", "yo y él", "yo y ellos", "yo y ustedes". Pero el problema no es tanto qué personas entran sino ver cuáles son las prácticas que se llaman nosotros, qué máquina se produce como nosotros. Y a partir de todo esto habría que pensar esa máquina como composición de operaciones y no como composición de personas."

Frente a esta forma de constitución colectiva, se opone algo que a nosotros nos gustaría calificar como "obstáculo específico": la subjetividad asistencial. La subjetividad asistencial consistiría en pensar que siempre que hacemos algo, tenemos que hacerlo no para nosotros sino "para otros". La práctica asistencial siempre organiza la experiencia dividiendo a quienes participan de ella según dos categorías: el asistente y el asistido. De esta manera, siempre se está buscando a quienes tienen "más necesidades que nosotros", a alguien al que identificamos con la carencia y con el desvalimiento, para poder ayudarlo. Esto ayuda a cristalizar esto lugares diferenciados del asistente y el asistido. El par asistente/asistido hace serie con los pares representante/representado, dirigente/dirigido, etc., obstruyendo la lógica del proceso asambleario.

Esta obstrucción (y las operaciones que se realizan para sortearla) aparece de maneras muy concretas en la experiencia asamblearia: para nosotros no se trata de oponer un "nosotros" de identidad asistencial con un nosotros de identidad autosuficiente. En ambos casos, se trata de un nosotros cerrado que, a lo sumo, intenta sostener ciertas relaciones con el exterior. En cambio, el nosotros compuesto de prácticas es un nosotros abierto, sin configuración estable, que es constantemente capaz de incorporaciones, que rompe con la lógica del "adentro" y el "afuera". Y esto tal vez sea una de las potencialidades más interesantes de las asambleas como espacios de autoorganización.

Los nosotros identitarios son nosotros constituidos por homogeneidades, nosotros que se hacen fuertes cuando todos se parecen entre sí, cuando piensan lo mismo. El nosotros de prácticas es un nosotros compuesto por diferencias. Si se homogeneiza, pierde su potencia que se encuentra, justamente, en la riqueza que producen personas diferentes, con recursos distintos, funcionando cooperativamente. En este sentido, las relaciones con quienes no forman parte de ese nosotros siempre se hace a partir de la siguiente pregunta: ¿bajo qué condiciones ellos y nosotros podemos empezar a construir un espacio común en el cual "ellos" dejen de ser "ellos" y "nosotros" dejemos de ser "nosotros", pudiendo componer nuestras diferencias?

Una situación donde se ponen en juego estas lógicas:

En las asambleas de los barrios céntricos, compuestas en su mayoría por gente que solía ser "de clase media", comienzan a ensayarse relaciones con gente que vive en barrios periféricos pero que cirujean en la zona. Algunas de estas experiencias de relación adoptan el modelo asistencial, "hay que hacer algo por ellos". Por ejemplo, la organización de la basura, separando los residuos no comestibles de los restos de comida. O recolectando ropa y alimentos que son distribuidos el día de reunión de la asamblea.

Pero otras experiencias intentan componer un nosotros entre "pobres" y "gente de clase media", experiencias de producción conjunta (por ejemplo, un proyecto de elaboración de milanesas de soja) 
que tienden a que, a partir de las herramientas y saberes diferentes que cada uno pueda aportar, se produzca una hibridación que suspenda las identidades fijas y nos permita encontrarnos con las potencias propias y ajenas, convertidas en potencias colectivas.

\section{La asamblea como espacio intergeneracional}

"Eso es algo que al poder lo aterroriza cuando los pibes se juntan con la experiencia de los más viejos.

No pueden hacer nada contra eso."

Un asambleísta de Plaza de la Cooperación

Desde el principio, en muchas asambleas se pudo notar la confluencia en este espacio de generaciones distintas. Jóvenes universitarios/desocupados/etc. y gente más grande, de la "generación de los '70". Creemos que la asamblea permitió un encuentro inédito entre estas dos generaciones. Inédito en el sentido de que fuera de las asambleas estos encuentros se producen según un sistema de jerarquías (familiares, laborales, etc.) mientras que en las asambleas, a consecuencia de su horizontalidad, estos órdenes estaban trastornados. Si una generación es, más que una franja etaria o intervalo de edades, un conjunto de formas comunes de plantear problemas y soluciones, en las asambleas conviven superpuestas y yuxtapuestas estas formas, pertenecientes a distintas generaciones. No hay forma de organizar, a priori, la validez de todos estos recursos. Son cada una de las prácticas y las intervenciones las que van definiendo, caso por caso, su pertinencia. De esta manera, la asamblea va produciendo las hibridaciones, las configuraciones intergeneracionales que mejor se adapten al desarrollo mismo de la experiencia asamblearia.

\section{El "devenir minoritario" de las asambleas}

Cualquiera puede empezar una asamblea. Las asambleas parten de ser un cúmulo de soledades que dejan de ser soledades cuando se organizan a sí mismas para hacer algo. Esa es la condición mínima de cualquier organización autónoma. Las asambleas barriales se organizan a partir de gente que vive cerca. Pero también existen otras formas de asociarse con otros. Por ejemplo, según los lugares donde uno trabaja, o donde uno estudia, etc. o según las cosas que uno le gustan (intereses éticos, estéticos, etc.) La cuestión es que la suma de todas estas organizaciones no componen una totalidad. Uno puede vivir en un barrio, trabajar en otro y estudiar en otro. Por lo tanto, más que una idea de sectorización del campo social se podría pensar en un entramado de redes superpuestas, una multiplicidad de planos donde lo más frecuente sea que cada uno de nosotros participemos en varios, experimentando diversas formas de asociación, pensamiento y construcción colectiva. 


\section{Sobre las intervenciones de los partidos políticos en las}

\section{asambleas}

Hay una alteración en las formas de intervención de los partidos políticos a partir del surgimiento de las asambleas, así como lo hubo luego de la emergencia de los movimientos piqueteros. Proponemos elaborar algunas hipótesis sobre esta alteración, sobre las configuraciones específicas que la lógica partidaria adopta en el medio asambleario.

Asambleas y partidos funcionan con lógicas diferentes. Los partidos buscan (o dicen) representar a cierta cantidad de individuos (una clase, un sector, toda la sociedad) y, en litigio con los otros partidos, ocupar (vía elecciones, vía golpe, vía revolución) el Estado y desde ahí definir la organización de la sociedad en general. En las asambleas no hay representación sino presentación. Lo que hace que una asamblea exista y funcione es que sea participativa (no representativa). $Y$ tampoco busca ocupar el Estado y desde ahí organizar la sociedad "en general" sino autoorganizar las relaciones dentro de colectivo singular y las relaciones con otras asambleas.

Entonces, las relaciones entre partidos y asambleas se pueden dar de dos maneras:

- o los partidos representan y conducen a las asambleas, orientándolas hacia la ocupación del Estado

- o las asambleas absorben las estructuras partidarias (o al menos parte de ellas) obligándolas a funcionar bajo la lógica participativa

Esta última opción termina siendo mucho más efectiva que la de intentar construir espacios "puros", expulsando a los partidos, ya que ahorra el tiempo y la energía de la confrontación y además, permite que las asambleas puedan apropiarse de ideas y saberes de los partidos, reinscribiéndolos bajo su propia lógica.

También es más difícil de producir en concreto: ¿cómo se hace para que cada militante partidario funcione con lógica asamblearia? ¿Cómo se hace que el militante partidario que llevamos dentro (que es en general, la forma dominante de la politización, por lo tanto su forma espontánea en "condiciones normales") funcione con lógica asamblearia?

Por ahora, la clave sería absorber más que enfrentar.

Un problema adicional: los partidos de izquierda, hasta el surgimiento de todas estas formas de autoorganización (asambleas, movimientos autónomos de desocupados, tomas de fábricas, etc.), se concebían a sí mismos mayoritariamente como "partidos de masas". La idea era que la ocupación del Estado ( $y$ el subsiguiente cambio social) se volvería posible acumulando la mayor cantidad de personas posibles dentro del partido. "Acumular" era la práctica militante básica. La participación en cualquier espacio social estaba orientada por esta tarea. Pero creemos que actualmente se ha operado un desplazamiento: del "partido de masas" al "partido de cuadros". No se trataría ya de absorber la totalidad del movimiento sino de hegemonizarlo, es decir, disputar la dirección del movimiento y lograr que éste adopte el programa elaborado por el partido. De este modo, los partidos pasan a concebir a las asambleas como "organismos" donde "las masas" eligen democráticamente uno u otro programa, una u otra dirección. Lo que queda excluida de esta concepción es la posibilidad de que las asambleas sean sitios de elaboración, además de lugares donde uno puede elegir entre 
propuestas elaboradas exteriormente. Porque si las asambleas producen sus propias orientaciones, son imposibles de ser direccionalizadas desde su exterior.

\section{Sobre la relación asambleas/Estado}

Un breve relevamiento de las diversas posiciones ensayadas hasta el momento por las asambleas ante el Estado:

\section{El exigitorio}

Una serie de tácticas que se organizan no ya para peticionar sino para exigir que el Estado realice determinadas acciones.

\section{El control de gestión}

De manera fragmentaria, algunas asambleas comienzan a pensar en mecanismos de control de la gestión, no sólo de los organismos del Estado, sino también de las empresas privatizadas.

\section{La reabsorción}

Sostenida en la pregunta "¿cómo volver a hacer habitable la representación?", esta posición busca una reformulación del sistema representativo (pensada algunas veces en términos de reforma política, otra en recambio de dirigentes y a veces por la vía de fundación de nuevos partidos políticos) de manera que vuelva a tener capacidad de alojar a quienes hoy construyen espacios de autoorganización.

\section{La prescripción de una distancia}

La insistencia en la consigna "que se vayan todos", más que una exigencia, tiene el valor de sostener la distancia que separa a las asambleas del campo de la representación.

\section{La utilización como recurso}

Algunas asambleas ensayan tácticas que consisten en la elaboración de proyectos autónomos pero no descartan la "utilización" de ciertos recursos estatales, que se vuelven disponibles a partir de la lucha o el aprovechamiento de intersticios y resquebrajamientos en la lógica estatal. (Un poco a la manera en la que los movimientos de desocupados autónomos hacen uso de los planes trabajar para sostener sus experiencias de construcción de nuevas formas de vida social).

\section{Después de las asambleas}

Se nos ocurren varios "después" posibles. No tanto como predicciones sino como presencias actuales de proyectos que hoy circulan en las asambleas. Sin pretender ser exhaustivos, podemos pensar en cuatro:

\section{Disolución}

Las asambleas, o su gran mayoría, desaparecen. Pero queda una memoria latente, una experiencia de masas sobre autogestión, autoorganización disponible como recurso para ser empleada en situaciones futuras. 


\section{Mutación}

Las asambleas se redefinen a partir de su actividad principal: compra comunitaria, biblioteca popular, publicación barrial, espacio de diálogo, etc. De alguna manera, esto es lo que está sucediendo en muchas asambleas, que encuentran en cierta actividad su "potencia específica" y delimitan de esta manera su campo de acción, concentrándose en la intensidad y no tanto en la extensión. De producirse tal delimitación, la asamblea muta, se convierte en otra cosa: un espacio de autogestión local que se sostiene en una tarea específica.

\section{La asamblea como espacio de iniciativas populares}

La asamblea se convierte en un centro de intercambio y elaboración de propuestas, en un nudo de una red de experiencias barriales de autogestión. La idea sería que lo que hoy por hoy son las comisiones se autonomizan de la asamblea, dejan de ser "partes" para ser proyectos en sí mismos. Y la asamblea se convierte en el lugar donde uno va a encontrarse con otros para proponer o inventar actividades o para informarse sobre las ya existentes. La asamblea ya no sería la generadora de estas prácticas sino un espacio de socialización, de intercambio de información sobre los espacios del barrio que desarrollan estas iniciativas.

\section{Reabsorción en el lazo representativo}

Esta posibilidad está presente tanto dentro de las asambleas como desde fuera de ellas, en los partidos, los medios de comunicación y en el Estado. En palabras de un funcionario del Estado nacional "toda esta gente que participa de las asambleas lo que tiene que hacer es organizarse en partidos que defiendan sus intereses". Las formas de retorno al campo de la representación son variadas: las asambleas se podrían convertir en instancias fiscalizadoras o de control de la acción del Estado y de las empresas privatizadas o se podrían fundar nuevos partidos políticos surgidos "desde el corazón" de las asambleas. Esta sería la única de las posibilidades con las que seríamos abiertamente críticos. Queremos explicar porqué:

Si pensamos a las asambleas como la negación de la representación, estas reabsorciones serían la cancelación de la experiencia asamblearia, es decir, la negación de la negación de la representación. La negación de la negación no nos devuelve, por supuesto al punto de partida, la representación original, sino que produce una síntesis, la "representación reformada", que posiblemente sea aún más efectiva en su forma de dominación y pasivización de los representados. No a pesar, sino justamente a causa de la incorporación de ciertos mecanismos asamblearios o de democracia directa. Probablemente, sea una representación más habitable que la que tenemos (¿teníamos?). Pero, en todo caso, la ruptura queda cancelada. Esa representación reformada no será la mutación de las asambleas sino las huellas de su desaparición. $\mathrm{Y}$ los que sigamos intentando ser fieles al $19 y 20$ y a la experiencia asamblearia tendremos que inventar nuevas rupturas.

(C) gradocero. Se permite la copia y la reproducción literal de su totalidad por cualquier medio, siempre y cuando se preserve 


\section{Formato de citación}

Gradocero (2003). Pensamiento asambleario en Argentina (12 herramientas de autoorganización social). Athenea Digital, 3. Disponible en http://antalya.uab.es/athenea/num3/gradocero.pdf 